RESEARCH ETHICS

\title{
Do drug firms hoodwink medical journals? Or is something wrong with the contribution and integrity of declared authors?
}

\author{
E J Wagena, P Knipschild
}

J Med Ethics 2005;31:307. doi: 10.1136/jme.2004.008433

$\mathrm{T}$ avoid the necessity of relying on trust in the matter of scientific authorship, most biomedical journals have adopted the uniform requirements for manuscripts submitted to biomedical journals, which are produced by the International Committee of Medical Journal Editors (ICMJE). ${ }^{1}$ The scientific journals that are members of the ICMJE routinely ask contributors to sign a statement that they accept full responsibility for the conduct of the study, had access to the data, and controlled the decision to publish. They even request and publish information about the contributions of each person named as having participated..$^{2}$ It turns out, however, that these requirements do not seem to guarantee the integrity of publications. The editor of a major medical journal wrote: "editors of medical journals worry that we sometimes publish studies where the declared authors have not participated in the design of the study, had no access to the raw data, and had little to do with the interpretation of the data". ${ }^{3}$ He justifiably states that readers as well as editors are thus being deceived"; but by whom exactly are they hoodwinked? ${ }^{4}$

Besides the editors of medical journals there are two other parties involved: the researcher, and the party who funds the study. Although pharmaceutical companies financially support most of the studies on drugs, one could argue that government agencies fulfil a similar role in the research they sponsor. They too can have a clear interest in a specific study outcome. In the case of drug related research, the pharmaceutical companies are being blamed for hiring so called ghostwriters and looking for established academics or researchers who are willing to be named as authors. Susanne Rees, a former editorial assistant with a medical writing agency, disclosed: "medical writing agencies go to great lengths to disguise the fact that the papers they ghostwrite...are ghostwritten on behalf of pharmaceutical companies and not by the named authors". ${ }^{4}$ But are the pharmaceutical companies in these cases really to blame? In our opinion it is naïve to expect pharmaceutical companies, who have huge financial interests in drug related research, to behave as if they were independent academics. The primary objective of the industry is to sell a product and make money.
We believe that academics and researchers, who are being invited by the pharmaceutical companies to be named as (lead) author and to accept being so named without having written the article (or in general without having complied with the uniform requirements for manuscripts), lack scientific responsibility and must be held accountable for any (putative) mistakes.

Although exact figures are lacking, ghostwriters are estimated to write up to $50 \%$ of all articles on drugs in the major medical journals. ${ }^{4}$ It seems that the declared authors who lend their reputations (indirectly) to the pharmaceutical companies, not only give these companies a free rein to publish favourable results, but also give them the opportunity to refrain from publishing the unfavourable results. Do drug firms really hoodwink medical journals, or is something wrong with the contribution and integrity of declared authors? In our view, the heart of the matter is the scientists' professional commitment to truth and honesty.

\section{Authors' affiliations}

E J Wagena, P Knipschild, Maastricht University, Care and Public Health Research Institute (CAPHRI), Department of General Practice, Maastricht, The Netherlands

Correspondence to: Edwin J Wagena, Pulmonary Rehabilitation Centre Hornerheide, PO Box 4080, 6080 AB Haelen, The Netherlands; edwinwagena@proteion.nl

Accepted for publication 17 February 2004

\section{REFERENCES}

1 International Committee of Medical Journal Editors. Uniform requirements for manuscripts submitted to biomedical journals http://www.icmje.org (accessed 12 Jan 2004).

2 Rennie D, Flanagan A, Yank V. The contributions of authors. JAMA 2000;284:89-91.

3 Smith R. Maintaining the integrity of the scientific record. Editors make a move. BMJ 2001;323:588.

4 Barnett A. Revealed: how drug firms "hoodwink" medical journals. The Observer 7 Dec 2003 http://observer.guardian.co.uk/uk_news/story/ $0,6903,1101680,00 . h t m l$ (accessed 2 Nov 2004). 